\title{
Effect of a Shot Peening Pre Treatment on the Fatigue Behaviour of Hard Chromium on Electroless Nickel Interlayer Coated AISI 4340 Aeronautical Steel
}

\author{
Marcelino P. Nascimento ${ }^{a}$, Marcelo A.S. Torres ${ }^{b}$, Renato C. Souza ${ }^{c}$, \\ Herman J.C. Voorwald ${ }^{a}$ \\ ${ }^{a}$ State University of São Paulo - UNESP/FEG/DMT \\ ${ }^{b}$ DME, 333, Ariberto Pereira da Cunha Ave, \\ 12500-000 Guaratinguetá - SP, Brazil \\ ${ }^{c}$ Department of Materials, DEMAR/FAENQUIL, Lorena - SP, Brazil
}

Received: August 28, 2001; Revised: May 1, 2002

\begin{abstract}
Multiple layer systems of coatings are considered to have larger resistance to crack propagation in comparison to coatings with simple layer. With regard to fatigue, it is possible to improve the resistance of a component with the application of shot peening treatment, whose compressive residual stresses delay or eliminate the initiation and propagation of fatigue cracks. The aim of this study is to analyse the effects on rotating bending fatigue behaviour of hard chromium electroless nickel multilayer system coated AISI 4340 high strength steel submitted to shot peening pre treatment. Results indicated that the interaction between the shot peening process with the multilayer system was not satisfactory, resulting in intense delamination. Fracture surface analysis by SEM was performed toward to identify the fatigue crack origin, as well as the coatingsubstrate delamination process.
\end{abstract}

Keywords: shot peening, fatigue, AISI 4340 aeronautical steel, multilayer system of coating

\section{Introduction}

Many are the possibilities of metallic coatings for both decorative and functional applications. Functional deposits are designated to improve the service life of coated piece'. Among the functional applications stand out the hard chrome and electroless nickel coating ${ }^{2}$.

The electroless nickel coating has high hardness, wear and corrosion resistances, as well as high covering capacity. In the aeronautical industries they are basically used toward the recuperation of consumed pieces².

On the other hand, hard chromium electroplating (above $2,5 \mu \mathrm{m}$ thick) is used in several landing gear components as: shock absorber, hydraulic cylinders and shafts. However, it is well known that the hard chromium electroplating decrease the fatigue resistance of a component, which is attributed to high tensile residual stresses and microcracks density contained into the coating ${ }^{3}$. Thus, failure of the hard chrome plating is frequently governed by initiation and

*e-mail: pereira@feg.unesp.br

Trabalho apresentado no IV Coloquio Latinoamericano de Fractura y Fatiga propagation of these microcracks ${ }^{4}$. As a consequence, the aeronautical industries have been working in the sense of developing alternative coating processes or improve the current ones.

Multilayer systems of coatings are considered to have superior resistance to cracks propagation than coatings with simple layer. Bifurcation in the crack tip and deviation in its path when close to the interface are considered possible mechanisms of retention of crack propagation ${ }^{5}$.

On the other hand, it is also possible to improve the resistance of a component through shot peening superficial treatment, whose compressive residual stresses generated delay or eliminate the initiation and propagation of cracks ${ }^{6}$. Shot peening is a cold work process in which small spheres impact the surface of a piece. The impact of the spheres on the surface produces small dimples, creating a compressive residual stresses field below them ${ }^{6,7}$. These stresses produced on or under the surface of a piece can be as high as $50 \%$ of its yielding tensile strength? 
The aim of this study is to analyse the effects on rotating bending fatigue behaviour of hard chromium electroless nickel multilayer system coated AISI 4340 high strength steel submitted to shot peening pre treatment.

\section{Experimental Procedure}

\section{Material}

The present study has been conducted with samples of AISI 4340 steel, used in aircraft components where strength and toughness are fundamental design requirements. The chemical analysis of the material used in this research was: $0,39 \% \mathrm{C},<0,001 \% \mathrm{~S}, 0,69 \% \mathrm{Mn}, 0,74 \% \mathrm{Cr}, 1,70 \% \mathrm{Ni}$ and $0,23 \% \mathrm{Mo}$. The fatigue experimental program was performed on rotating bending fatigue test specimens machined from hot rolled and quenched and tempered bars according to Fig. 1. Before grinding machine the material was quenched from $815^{\circ} \mathrm{C}-845^{\circ} \mathrm{C}$ in oil $\left(20^{\circ} \mathrm{C}\right)$ and tempered in the range of $(520 \pm 5){ }^{\circ} \mathrm{C}$ for two hours.

The specimens were polished in the reduced section with 600 grit papers, inspected dimensionally and by magnetic particle inspection. After final preparation, samples were subjected to a stress relieve heat treatment at $190{ }^{\circ} \mathrm{C}$ for 4 hours to reduce residual stresses induced by machining. Average superficial roughness in the reduced section of the samples was $\mathrm{R}_{\mathrm{a}} \approx 2.75 \mu \mathrm{m}$ and standard deviation of $0.89 \mu \mathrm{m}$.

Rotating bending fatigue test were conducted using a sinusoidal load of frequency $50 \mathrm{~Hz}$ and load ratio $\mathrm{R}=-1$, at room temperature, considering, as fatigue strength, the complete specimens fracture or $10^{7}$ load cycles.

Five groups of fatigue specimens were prepared to obtain S-N curves for rotating bending fatigue tests.

- specimens of base material - AISI 4340;

- specimens of base metal and hard chromium electroplated, $100 \mu \mathrm{m}$ thick;

- specimens of base metal with intermediate electroless nickel plating layer $15 \mu \mathrm{m}$ thick and electroplated with hard chromium, $145 \mu \mathrm{m}$ thick;

- specimens of base metal shot peened with hard chromium electroplating, $100 \mu \mathrm{m}$ thick;

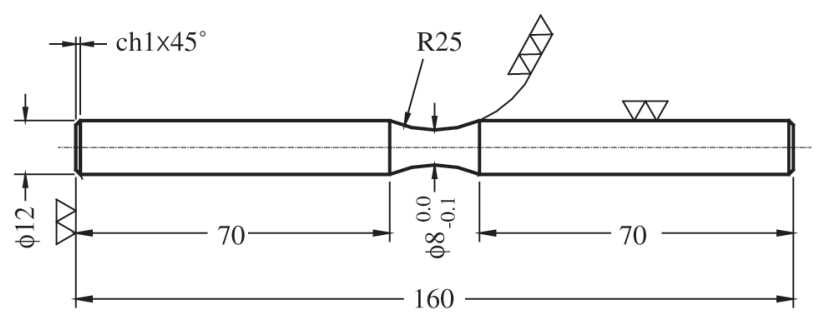

Figure 1. Rotating bending fatigue testing specimen.
- specimens of base metal shot peened with intermediate electroless nickel plating layer, $15 \mu \mathrm{m}$ thick, and electroplated with hard chromium, $145 \mu \mathrm{m}$ thick.

\section{Surface Treatments}

\section{Shot peening process}

The shot peening process was applied in accordance to MIL-S-13165C, with intensity of $0.008 \mathrm{~A}$, spheres S 230 of steel, and $200 \%$ covering. The superficial treatment was applied on fatigue specimens and just on reduced section and before coatings.

All coatings employed in this study were submitted to adhesion test in accordance with ASTM B 571, getting approbation.

\section{Electroless nickel deposition}

The electroless nickel deposition was made in a solution containing $20 \mathrm{~g} / \mathrm{L}$ of $\mathrm{NiSO}_{4}$ and $24 \mathrm{~g} / \mathrm{L}$ of $\mathrm{NaH}_{2} \mathrm{PO}_{2}$, with pH 5, of $82{ }^{\circ} \mathrm{C}$ to $88{ }^{\circ} \mathrm{C}$ and speed deposition of $8 \mu \mathrm{m} / \mathrm{h}$ to $10 \mu \mathrm{m} / \mathrm{h}$, resulting in coating with $12 \% \mathrm{P}$ (Ni-P alloy).

Before the superficial treatment applications the specimens were vapour degreased and alkaline degreased and desoxided in hydrochloric acid solution.

\section{Hard chromium electroplating}

The accelerated hard chromium electroplating was carried out from a chromic acid solution with $250 \mathrm{~g} / \mathrm{L}$ of $\mathrm{CrO}_{3}$ and $2.7 \mathrm{~g} / \mathrm{L}$ of $\mathrm{H}_{2} \mathrm{SO}_{4}$, at $55^{\circ} \mathrm{C}-60{ }^{\circ} \mathrm{C}$, with a current density from $55 \mathrm{~A} / \mathrm{dm}^{2}$ to $65 \mathrm{~A} / \mathrm{dm}^{2}$, and speed of deposition equal to $80 \mu \mathrm{m} / \mathrm{h}$. A bath with double catalyst, based on sulphate and without fluoride, was used. The term "accelerated "was used to characterise the high efficiency and fluoride free hard chromium electroplating.

Average surface roughness of the hard chromium electroplating was $\mathrm{R}_{\mathrm{a}} \approx 3.13 \mu \mathrm{m}$ in the reduced section and standard deviation of $0.79 \mu \mathrm{m}$, in the as-electroplated condition.

After all coatings, the specimens were subjected to a hydrogen embrittlement relief treatment at $190{ }^{\circ} \mathrm{C}$ for 8 hours, in accordance to ASTM E519.

Fracture surfaces analysis.

Analysis of fracture surface was carried out on rotating bending fatigue specimens by scanning electron microscope, model LEO 435 Vpi and Zeiss DSM 950.

\section{Results and Discussion}

\section{Tensile tests}

Mechanical properties of the material after heat treatment are: hardness of $39 \mathrm{HRC}$; yield tensile strength of 1118 $\mathrm{MPa}(0.2 \%$ offset $)$, ultimate tensile strength of $1210 \mathrm{MPa}$ and elongation of $14.9 \%$. 


\section{Rotating bending fatigue tests}

Figure 2 shows the $\mathrm{S} \times \mathrm{N}$ (Wöhler) curves of the rotating bending fatigue tests for all mentioned groups.

From Fig. 2, it is possible to observe the effect of the hard chromium plating on the fatigue strength reduction of the AISI 4340 steel. This is due to high tensile residual stresses and microcracks density contained in the coating, as mentioned in previous studies ${ }^{3}$.

\section{Effect of the electroless nickel layer}

Figure 2 shows the benefit effect of the electroless nickel interlayer application on the fatigue life of AISI 4340 steel hard chromium electroplated. This behaviour may be attributed to the largest toughness/ductility and compressive residual stresses contained in the electroless nickel plating, which, probably, arrested or delayed the microcrack propagation from the hard chromium external layer ${ }^{8}$. Basically, residual stresses in the electroless nickel plating are dependent on its phosphorus content, being tensile between $4 \% \mathrm{P}$ and $9 \% \mathrm{P}$ and compressive below $4 \% \mathrm{P}$ and in the range of $10 \% \mathrm{P}$ to $12 \% \mathrm{P}^{9,10}$. The nickel plating ductility also changes with phosphorus content, being minimum at $10 \% \mathrm{P}$ and maximum at $12 \% \mathrm{P}^{9}$.

The application of several layers of coatings is a way to obtain high hardness in combination with high toughness. This system is considered to have superior properties than coatings with simple layer, including to abrasion and erosion resistances. Wiklund et al. ${ }^{4}$, mentioned that coatings with multiple layers have larger resistance to cracks propagation than those with simple layer. Crack tip bifurcation due to plastic deformations and deflection of its path, when close to the interface, may be possible mechanisms of inhibition of cracks in coatings with multiple layers. Differences

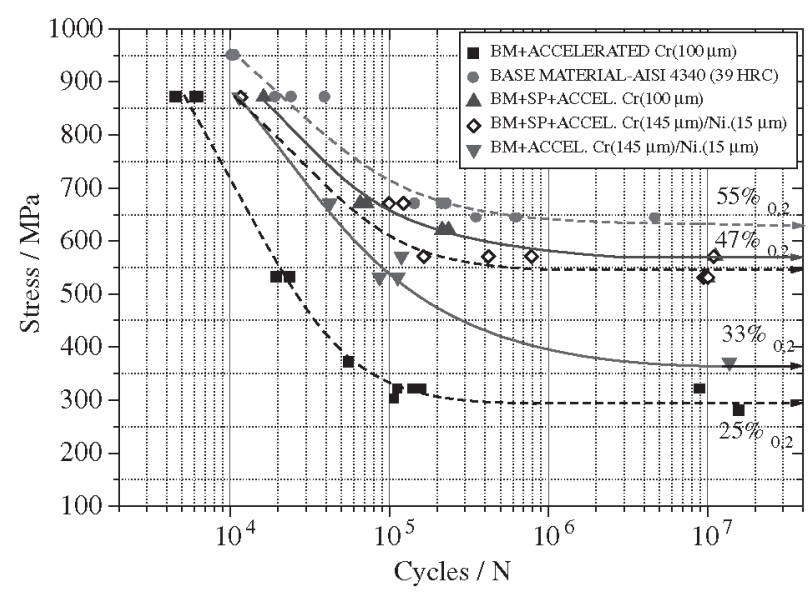

Figure 2. S-N comparative curves of the all cases analysed in this study. on materials properties, such as Young's Modulus, elasticity, toughness and morphologies, when a crack pass through the interface between coatings, increase the possibilities of the crack to deflect or to bifurcate in several other, so, reducing the intensity stress factor at the crack tip and resulting in a more toughness coating.

\section{Effect of the shot peening superficial pre treatment}

From Fig. 2, it can be observed the excellent recuperation on fatigue strength of the groups submitted to shot peening pre treatment. It is well known that the process induces compressive residual stresses at the surface and subsurface, in a depth which depends on the intensity, size, material and hardness of the shot and percentage of recovering $^{11}$. The compressive residual stresses arises as a result of the resistance of the adjacent area of the material to the plastic deformation caused by the shot, which act arresting or delaying the cracks nucleation/propagation ${ }^{11-13}$.

Analysing the curves from the Fig. 2, it is also possible to observe practically the same fatigue behaviour of the hard chrome plated specimens submitted to shot peening pre treatment, with and without the electroless nickel intermediate layer (both inferior to the base material without coatings). This can means that the interaction of compressive residual stresses contained in the intermediate layer of electroless nickel with one contained at the surface of the base material (originated by the shot peening treatment), did not result in the expected increase in fatigue life when compared to the specimens shot peened and covered with simple layer of accelerated chrome*. This fact may be attributed to the compressive residual stresses superposition between them. That is, the compressive stresses contained in a layer may generate tensile stresses at the adjacent surface. This implicates that it cannot be appropriated to combine, consecutively, coatings, which contain similar residual stresses, but to alternate them through coatings with opposed residual stresses. On the other hand, this consideration implicates that the tensile residual stresses contained in the hard chrome plating would induce compressive residual stresses in the substrate. This is referenced by Horsewell ${ }^{5}$, who mentions that the chrome layer contraction during the eletroctroplating process generates high equi biaxial tensile stresses in the coating and compression stresses in the substrate. So, in the coating with simple hard chrome layer, the "benefit" given to the substrate is counteracted by the microcracks density contained in the coating, which when submitted to the tensile residual stresses action in addition to external loads, propagates and reduces the life fatigue of a component.

On the other hand, a delamination process were also verified in the electroless nickel/base material interfaces, submitted to the shot peening pre treatment, as can be observed from Fig. 3 (in spite of the best anchoring substrate/

* The influence of the hard chrome thickness variation from $100 \mu \mathrm{m}$ to 145 $\mu \mathrm{m}$ was not considered in function of the best performance of the samples covered with hard chrome (145 $\mu \mathrm{m}$ thick) on chemical nickel, (15 $\mu \mathrm{m}$ thick) in comparison with hard chrome plated samples, $100 \mu \mathrm{m}$ thick. 


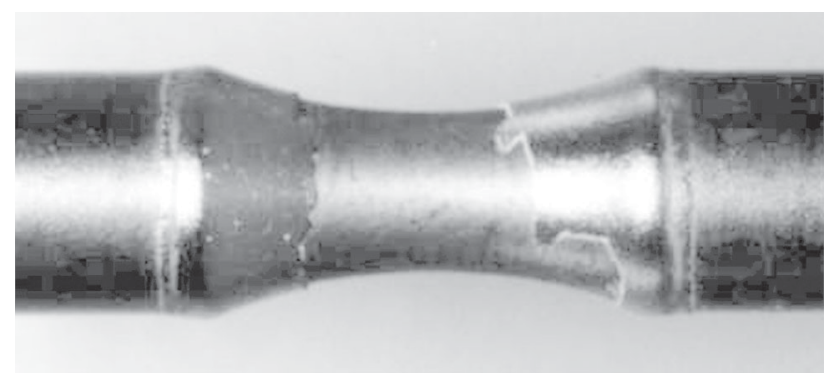

Figure 3. Delamination of the electroless nickel layer/base metal shot peened interface

coating caused by the superficial deformations induced by the shot).The observed delamination may probably be due to the residual stresses balance between base material and coating.

Another way to explain the delamination phenomena is presented by Y. Sugimura \& S. Suresh ${ }^{15}$, who showed experimentally that the conditions for a fatigue crack arrest or growth (in Mode I), through the interface between different solid materials, are governed by the direction in which it approaches the interface (if perpendicular or not), and if it comes from the more ductile/toughness material or from the more fragile one. It was verified that in simple and ductile layer coatings, the propagation occurs until the plastic zone at the crack tip touches the interface with the substrate (fragile). At this moment, the crack growth rate decreases, causing the crack arrest. Any attempt in forcing the crack propagation from the most ductile material to the most fragile (as increasing $\Delta \mathrm{K}$ ), will cause the crack tip deflection toward the substrate/coating interface, causing delamination. The crack will restart in a different area (for example, a stress concentrator) and will propagate into the base material. On the other hand, if the coating is more fragile than the substrate, the original crack of this coating will cross the interface and will penetrate in the substrate without impediment, increasing the $\Delta \mathrm{K}^{15}$. With the application of a more ductile intermediate layer, the surface original crack will growth through the layer (fragile) and will cross the interface and the intermediate layer, easily. However, when the plastic zone at the crack tip touches the interface coating / substrate (more strength), the crack will be retained even before to touches this interface. The loading sequence will just be to deflect and/or to bifurcate the crack tip, which will occur, also, close to the interface (and not in the interface). Thereby the delamination will be imminent. Figure 4 illustrates the whole path of a crack that began at the surface and propagated in direction to the base material, simulating the situation used in this study, based on the previously mentioned considerations.

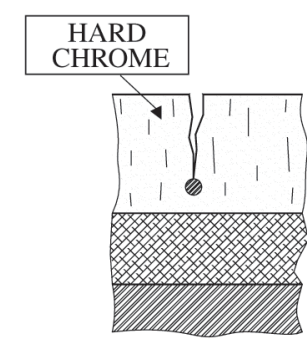

(a)

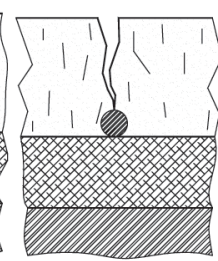

(b)

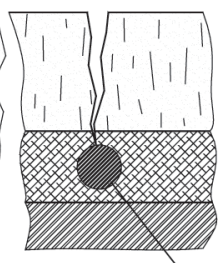

(c)

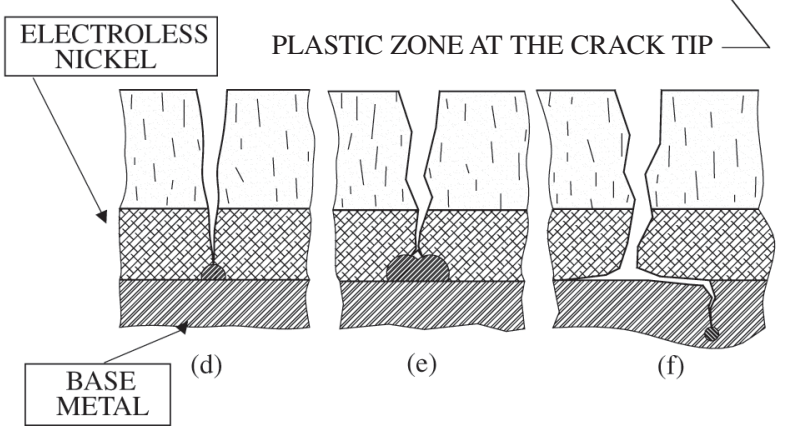

Figure 4. Simulation of the crack propagation in the multilayer system.

However, in spite of the electroless nickel coating is more ductile with regard to the external hard chrome plating, the propagation of cracks coming from this external layer was not easy. The retention of several cracks originating from the hard chrome layer was verified, according to Fig. 5 b. This means that there is a great contribution of the residual stresses on the fatigue cracks growth process, which is not necessarily correlated to the ductile or fragile nature of the material. That is, the residual stresses can be compressive or tensile and present in materials both fragile and ductile.

\section{Analyses of the fracture surfaces}

The fracture surfaces are illustrated in Figs. 5 and 6. One sees, from Figs. 5a and 5b, the uniformity in both thicknesses of electroless nickel and accelerated hard chrome; radial microcracks along the thickness of the accelerated hard chrome coating, which they did not growth in direction to the substrate, perhaps, inhibited by the electroless nickel intermediate layer. Also, the excellent adherence between hard chrome and electroless nickel layers and delamination between this last one with the substrate can be observed.

Figures $6 \mathrm{a}$ and $6 \mathrm{~b}$ show perfectly the effect of shot peening application on the retention or retardation of the fatigue cracks propagation. It is noticed that the cracks growth only after, perhaps, the compressive residual stresses field, either converging (a) or diverging (b). 


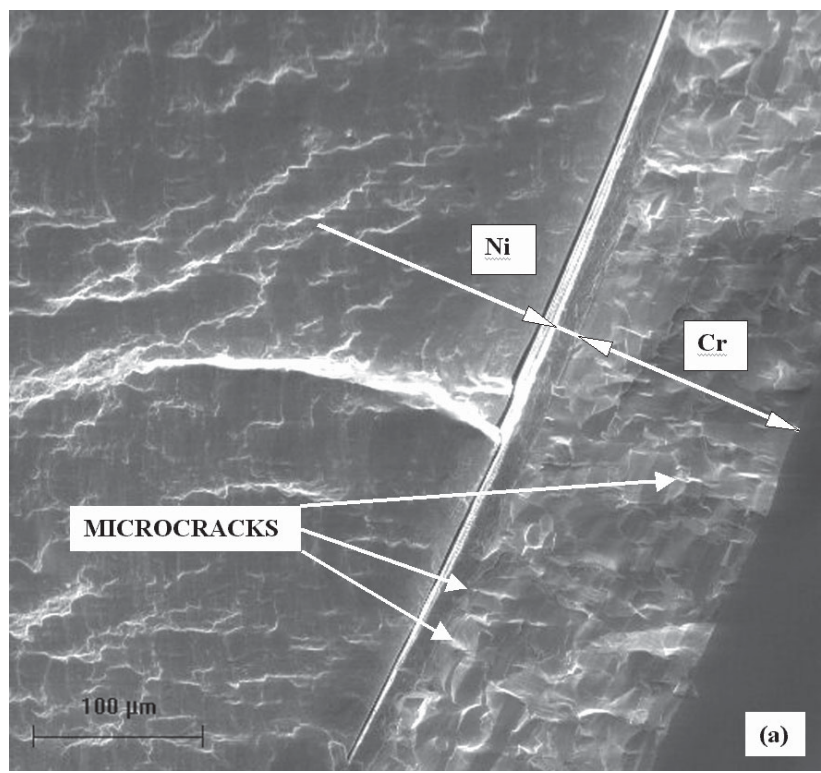

Figure 5a. Fracture surface of accelerated hard chromium $(145 \mu \mathrm{m})$ on electroless nickel $(15 \mu \mathrm{m})$ plating, unshot peened.

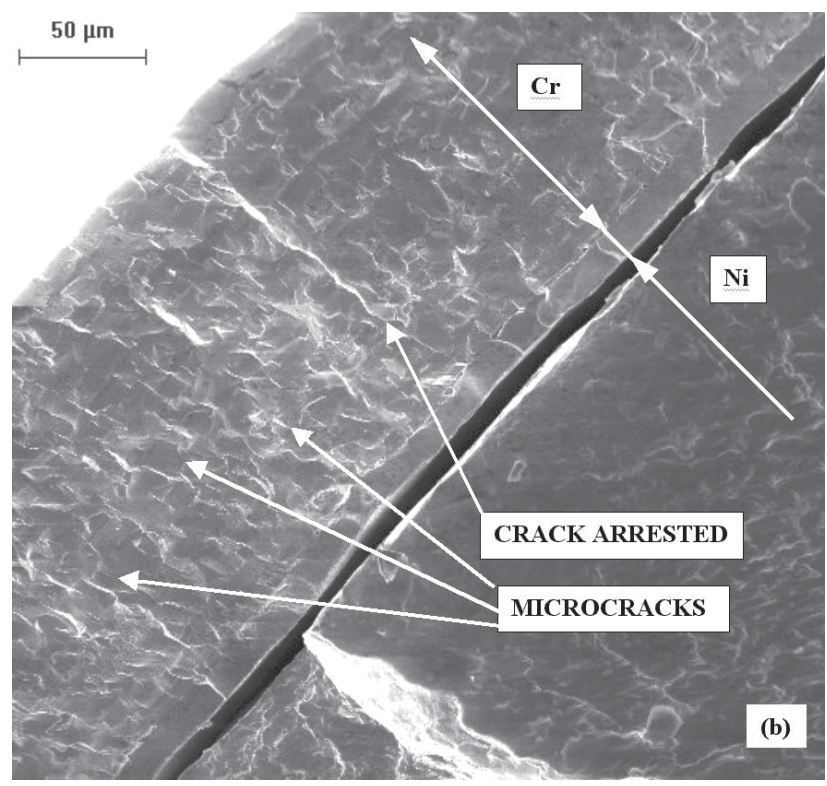

Figure 5b. Fracture surface of accelerated hard chromium $(145 \mu \mathrm{m})$ over electroless nickel $(15 \mu \mathrm{m})$ plated specimen submitted to shot peening pre treatment.

\section{Conclusions}

1. Electroless nickel intermediate layer application resulted in the recovery of the fatigue life of AISI 4340 high strength steel accelerated hard chromium coated. The electroless nickel intermediate layer was capable to inhibit or to retain the propagation of many origi-

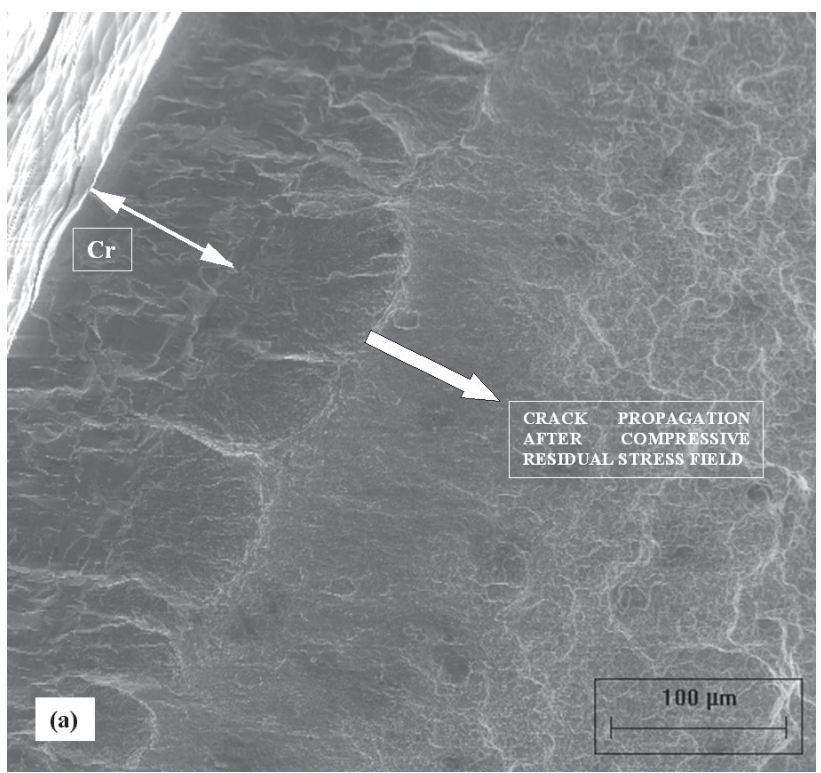

Figure 6a. Fracture surface of accelerated hard chromium electroplated specimen, $100 \mu \mathrm{m}$ thick, submitted to shot peening pre treatment.

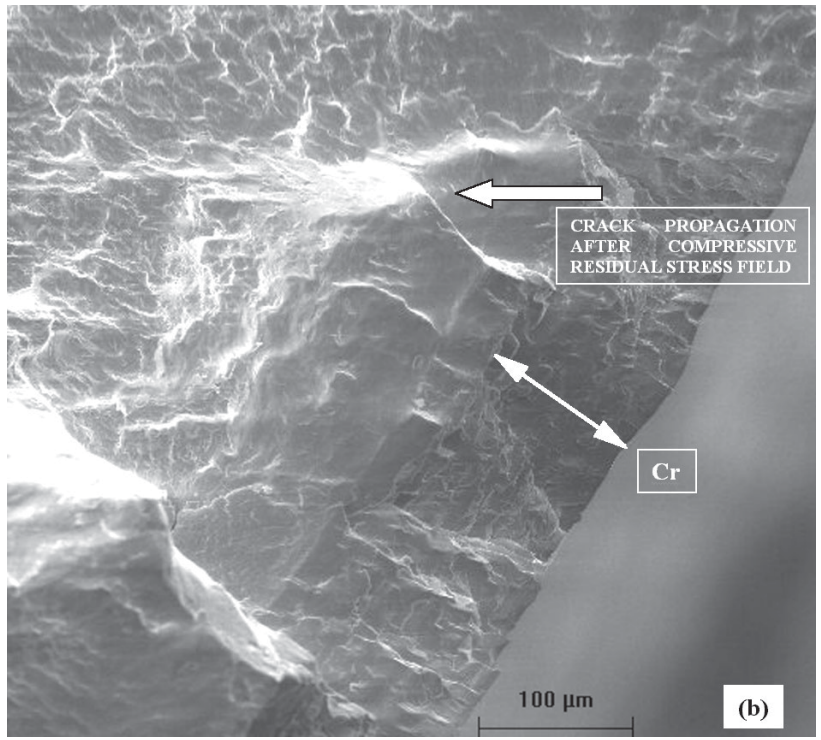

Figure 6b. Fracture surface of accelerated hard chromium electroplated specimen, $100 \mu \mathrm{m}$ thick, submitted to shot peening pre treatment.

nal cracks from the hard chromium external layer.

2. On accelerated hard chromium plated specimens containing an electroless nickel intermediate layer no shot peened, small delaminations (Fig. 5a), were observed.

3. From specimens submitted to shot peening pre treatment the delamination was more intense, around all coating/substrate interface (Fig. 5b). This suggests that, 
perhaps it is not interesting to put upon different layers containing compressive residual stresses, but to alternate them with layers containing tensile residual stresses or coatings free of stresses.

4. Hard chromium plated specimens and hard chromium on electroless nickel plated specimens, both shot peened, presented, practically, the same fatigue behaviour.

5. Accelerated hard chromium electroplating proved to have an excellent adherence to the AISI 4340 steel and to the electroless nickel intermediate layer. On the other hand, the delamination at intermediate electroless nickel layer-substrate interface was observed too.

\section{Acknowledgment}

The authors are grateful to EMBRAER-LIEBHERR/ EDE, CTA/AMR, FAPESP, CAPES and FUNDUNESP by the support.

\section{References}

1. Tyler, J.M. Metal Finishing, p. 11-14, October/1995.

2. Vasconcelos, S.M.B. Estudo da influência dos tratamentos superficiais de cromo duro e níquel químico na vida em fadiga do aço de alta resistência, ABNT 4340, Trabalho final de graduação, Escola de Engenharia Industrial, E.E.I., São José dos Campos/SP, 1992.
3. Nascimento, M.P.; Souza, R.C.; Pigatin, W.L.; Voorwald, H.J.C. Surface \& Coatings Technology, v. 138, n. 2-3, p. 113-124, 2001.

4. Wiklund, U.; Hedenqvist, P.; Hogmark, S. Surface and Coatings Technology, v. 97, p. 773-778, 1997.

5. Horsewell, A. Materials Science and Technology, v. 14, p. 549-553, June/1998.

6. Blastibrás, Tratamento de Metais Ltda., Catálogo Técnico, São Paulo/SP, Brasil.

7. Metal Improvement Company, Inc., M.I.C. Shot peening Applications, Technical booklet, $7^{\text {th }}$ edition, 1999.

8. Nascimento, M.P.; Voorwald, H.J.C.; Pigatin, W.L.; Souza, R.C. COTEQ'99, Rio de Janeiro,RJ, p. 85-88, 1999.

9. Duncan, R.N. VIII EBRATS, p. 139-148, 1994.

10. Duncan, R.N. VI EBRATS, v. II-III, 1989.

11. Kobayashi, M.; Matsui, T.; Murakami, Y. International Journal of Fatigue, v. 20, n. 5, p. 351-357, 1998.

12. Torres, M.A.S.; Voorwald, H.J.C.; Nascimento, M.P.; Pigatin, W.L. IV CIDIM, Santiago do Chile, Chile, v. II, novembro/1999.

13. Sridhar, B.R.; Ramachandra, K.; Padmanabhan, K.A. Journal of Materials Science, v. 31, p. 5953-5960, 1996.

14. Wu, Y.; Zhang, Y.; Yao, M. Plating and Surface Finishing, p. 83-85, April/1995.

15. Sugimura, Y.; Suresh, S. Ceramic Coatings, ASME, American Society for Mechanical Engineers, v. 44, p. 9-14, 1993. 